Geopolítica(s) Revista de estudios sobre espacio y poder ISSN: 2172-3958

\title{
Re-entendiendo el extractivismo en América Latina
}

Gian Carlo Delgado (2013) Ecología política del extractivismo en América Latina: casos de resistencia y justicia socio-ambiental. Ciudad Autónoma de Buenos Aires: CLACSO (Ebook). 588 pp. ISBN: 978-987-1891-61-0.

El campo de la ecología política es un campo de investigación relativamente nuevo. Aunque posee raíces que se conectan hasta la década de los 70 del siglo pasado, es desde finales de los 90 y principios de este último siglo que comienza ya a hablarse de ésta como una rama autónoma en ciencias sociales. Asimismo, la ecología política ha ido bebiendo de otras ramas vecinas y es transversal a ellas, como la ecología marxista, la economía ecológica, la geografía crítica, la historia ambiental, la antropología social y la sociología política, por nombrar a las más relevantes, de la que finalmente se ha despegado para generar una metodología específica de acercamiento a su objeto de estudio.

La necesidad de entender las dinámicas de apropiación de la naturaleza propias de este sistema económico, en la que las relaciones de poder entre los diversos actores (comunidades locales, empresas privadas y Estado) juegan un papel fundamental en la definición del modo en que los recursos naturales serán explotados, han hecho que la ecología política se vuelva una herramienta útil para entender de manera profunda las implicaciones reales de estos distintos procesos de explotación natural a diferentes escalas, desde lo local, a lo regional y a lo global. La ecología política ayuda a entender no sólo las causas sino también las consecuencias de las distintas formas de acumulación y apropiación, evidenciando las dinámicas subyacentes a éstas.

Una de las regiones del globo donde se ha vivido y se sigue viviendo este tipo de prácticas es Latinoamérica. Aquí, la relación capital (transnacional), grupos humanos y naturaleza se encuentran en una permanente tensión, y la ecología política ha realizado aportes valiosos en el camino de revelar y evidenciar las consecuencias del extractivismo en cada país. Más allá del tiempo histórico que se analice o el signo del gobierno en el poder, la dependencia y explotación excesiva de la naturaleza ha sido un lugar común permanentemente en su historia.

Con la entrega de Ecología política del extractivismo en América Latina: casos de resistencia y justicia socio-ambiental, coordinado por Gian Carlo Delgado Ramos, el Consejo Latinoamericano de Ciencias Sociales (CLACSO) sigue la línea de su serie de publicaciones sobre ecología política que inicio en el año 2002, y aporta a este campo un interesante paso en la construcción de una escuela latinoamericana en este ámbito. Aquí se recogen trece colaboraciones de investigadores e investigadoras que detallan una variedad de casos en diversos países latinoamericanos. Si 
entendemos a la ecología política como un espacio que permite equilibrar lo teórico y lo práctico, estas aportaciones que encontraremos aquí se centrarán en engranar especialmente lo segundo, a través de la aplicación a estas distintas experiencias de los planteamientos teóricos construidos por académicos como Martínez-Alier, Alimonda, Escobar y Leff, entre otros.

La lectura de estas páginas apela directamente a entender todas estas experiencias de (neo)extractivismo de una manera distinta a la lógica económica dominante de aprovechamiento y las supuestas bondades del modelo extractivista. Minería metálica o no metálica, agua, recursos forestales, biodiversidad, gestión de residuos y otros similares, son algunas de las temáticas que se tocan en cada uno de los artículos, y que van más allá del mero análisis antropocéntrico, sino que es ahora la naturaleza la que se establece en el centro del análisis, como un sujeto propio de explotación y al mismo tiempo como espacio físico donde se desenvuelven los conflictos, de modo que permite la visualización de las causas y consecuencias de estás dinámicas para sí misma y para los grupos humanos que viven en y de ella. De estos últimos se verá, además, cómo ha sido su conformación y/o transformación como sujeto subalterno en resistencia, dependiendo de los procesos específicos de intervención en la naturaleza.

Llama la atención las similitudes existentes prácticamente en todos los casos incluidos, aunque si mantenemos presente que Latinoamérica, como región global, ha mantenido un rol casi inmutable de proveedor de materias primas desde que fue incorporado al sistema-mundo en el siglo XV — rol que 500 años después aún marca su trayectoria geopolítica y económica-, convirtiéndose en la región más desigual del planeta, encaja perfectamente.

Actualmente, parece que tras cualquier modelo de desarrollo aparece subyacente siempre la lógica extractivista o de explotación intensiva de la naturaleza, sea éste de un lógica neoliberal (inversión transnacional defendida por la institucionalidad del Estado) o en las alternativas políticas-económicas que han ido apareciendo en algunos países, en los que su propuesta ha optado igualmente por un (neo)desarrollismo en el que el Estado es el que mantiene una mayor participación en la explotación natural y reparte esos beneficios de manera más amplia dentro de su población. Esta última, aunque procura generar formas menos dependientes del mercado, mantiene la misma mecánica de inserción de la región en la división internacional del trabajo. Por lo que, en todos los casos, en el espacio físico donde se realiza la extracción o explotación natural surge una resistencia natural, principalmente de las comunidades que habitan ese territorio y que se verán perjudicados por las actividades propuestas. Todo esto facilitado por una laxa normatividad y un escaso control de parte del Estado de las normativas existentes, y un particular desempeño de los medios de comunicación, que permite criminalizar a estos grupos subalternos que protestan y se movilizan para evitar el desastre de sus modos de vida.

La escala temporal utilizada por las diferentes investigaciones expuestas es dispar, pero con referencias compartidas. Por lo que encontraremos análisis que parten desde unas cuantas décadas hacia atrás, y algunas otras que tirando del hilo que encontraran que muchas de las raíces de las dinámicas de apropiación de la naturaleza pueden ser encontradas desde la época colonial. Y he aquí una de las mayores aportaciones desde Latinoamérica hacia la ecología política, cualidad que marca su 
inclusión particular en el desarrollo y construcción de esta escuela. En la cual al unir la historia ambiental con la escuela decolonial, permite entender de manera más amplia el desarrollo ambiental, económico, político y cultural de esta región, generando no solo nuevas formas de entender lo que ha ocurrido, sino permitiendo visualizar nuevas alternativas a esta inercia histórica.

También es importante caer en cuenta que, a pesar de existir similitudes y transversalidades en las dinámicas y tensiones existentes en cada una de las realidades expuestas en este compendio, no en todos los casos la resistencia procede del mismo modo. Y aquí, los casos presentados de conflictos actuales se los puede entender o clasificar en base a dos niveles. En un primer nivel es posible entender que el conflicto y las soluciones se enmarcan dentro del campo de lo técnico y lo institucional vigente. Es decir, en casos como la explotación mineral en Río Colorado (p. 125) o petrolera en Llancanelo (p. 123), en la Argentina, o la gestión de las Fuentes de agua en el Valle de México (p. 43), el conflicto reside y se trata de resolver dentro de los modos de gestión posibles, en una disputa que busca generar acuerdos para una explotación o una administración adecuada de los recursos, sin poner en duda la lógica interna y de valores del extractivismo.

En el segundo nivel, la tensión se desenvuelve también en el campo institucional, pero además existen connotaciones en las que se intenta transgredir este nivel y los límites se expanden y se encuentran dentro del campo de lo cultural y hegemónico. Para concebir lo anterior tenemos como ejemplo clave, aunque no el único, el de la explotación forestal y energética en el sur de Chile y la resistencia del pueblo mapuche (p. 19). Aquí, el sujeto subalterno ha ido sufriendo una transformación a lo largo del tiempo, y su oposición no solo se basa en la defensa de su espacio vital y modo económico de vida, sino que además contrapone en el espacio de lo simbólico los significados acerca del territorio, la naturaleza y la relación del ser humano con esta. Se enfrentan, a fin de cuentas, no sólo las alternativas de gestión técnica administrativa, sino que se llegan a enfrentar racionalidades y cosmovisiones completamente distintas acerca de la concepción de ser humano y su relación con la naturaleza. Antropocentrismo y biocentrismo. Es en este campo en donde se visualiza más explícitamente el aporte latinoamericano a la ecología política, en cuanto se junta la historia ambiental y los aportes de la escuela decolonial de esta región, se logra maximizar los frutos de este enfoque metodológico y académico. En este nivel, la lucha de las comunidades locales, especialmente aquellas que son originarias del continente, dejan de desarrollarse meramente en el plano económico, incluso sólo en el plano ambiental o el plano étnico. Por eso logran romper los límites de lo hegemónico, con nuevos discursos, conceptos y acciones, que terminan por construir un "ecologismo popular", como Martínez Alier ${ }^{1}$ lo denomina. Así, este tipo de resistencias al extractivismo, que no solo se enmarcan en la institucionalidad actual, es decir, por el derecho al agua, derecho a la tierra, derecho a autonomía, entre otros, sino también por lo que Moncada (p. 106) plantea, es una lucha por el "derecho del ser", una resistencia que nace de una simbiosis de la necesidad de procurar desarrollar modos de vida que permitan la continuidad y sostenibilidad entre lo ambiental, lo social y también lo cultural.

Joan Martínez Alier: "Macroeconomía ecológica, metabolismo social, y justicia ambiental”, Revista Historia Actual, 2011, vol. 9, núm. 9, pp. 148-168. 
Una mención adicional sobre la publicación en cuestión es la inclusión como anexo de mapas y descripciones breves con los actores implicados en decenas más de conflictos ambientales distribuidos por el resto del continente, lo que permite no solo ubicar mejor las zonas donde actualmente existen conflictos de este tipo, sino también hacer notar que los conflictos analizados en la publicación no son casos aislados dentro cada país, sino que revelan una sintomatología más profunda acerca de las acciones en pos de la apropiación de la naturaleza en todo el continente de un sistema económica que consiente la especulación con sus recursos y los devora sin freno.

Queda aún muchísimo trabajo para lograr una transformación estructural de los modos de apropiación y explotación de la naturaleza, pero eso solo puede ser motivación para que trabajos como éste sean espacios con una mayor amplitud metodológica, en donde se pueda re-entender el largo trayecto que ha recorrido esta región y su relación con la naturaleza, de manera que podamos seguir visibilizando procesos de acumulación por desposesión, acumulación por contaminación, distribución ecológica inequitativa, y otros conflictos sociales-culturales provocados por el extractivismo, que nos obligan a dar nuevas soluciones en pos de una verdadera justicia socio-ambiental.

Renato Fabricio Villavicencio Garzón Universidad Complutense de Madrid Email: rfvillavicencio@yahoo.com 